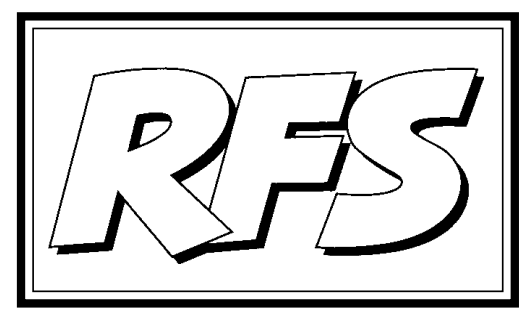

Revista de Fomento Social, 56 (2001), 461-473

\title{
Centroamérica ante la globalización e integración
}

Gert ROSENTHAL

\section{Introducción}

Agradezco a las autoridades del Banco de Centroamérica de Integración Económica, y, en especial, a su Presidente, Pablo Schneider, la gentil invitación que me hicieron para estar presente en esta conferencia. Ello me permite, en primer lugar, rendir un sentido homenaje al Banco, institución clave de la integración centroamericana, en su cuadragésimo aniversario. En segundo lugar, me ofrece la oportunidad de reunirme con amigos y colegas con los que he compartido por años $-y$, en algunos casos, por décadas- la vocación común de impulsar la integración en Centroamérica. Por último, me obliga a retomar preocupaciones seculares, pero un tanto

1 Representante permanente de Guatemala en Naciones Unidas y exsecretario general de la Comisión Económica para América Latina y el Caribe (CEPAL) de las Naciones Unidas. Texto de la intervención en la "Conferencia Regional: La Integración y el desarrollo de Centroamérica en el Siglo XXI", Tegucigalpa (Honduras) 27 de julio de 2001 (véase la crónica sobre esta conferencia en este mismo número). Agradecemos al autor su amable autorización para reproducir aquí el presente texto. 
abandonadas durante los últimos dos años, debido a mis actividades propias de alguien quien representa a su país ante las Naciones Unidas en Nueva York.

Desde luego, he seguido el tema de la integración, y aún más los acontecimientos en Centroamérica, como una preocupación permanente. Pero no es lo mismo dar ese seguimiento desde la distancia que estar involucrado cotidianamente en la política pública nacional o regional ${ }^{2}$ en Centroamérica. Con todo, la distancia también ofrece la oportunidad de una visión acaso menos apasionada; algo así como la posibilidad de advertir el bosque, más que los arboles individuales. Por eso, me atrevo a compartir con ustedes algunas inquietudes, precisamente sobre el tema que se me ha asignado: Centroamérica ante la globalización e integración.

Esa preocupación se puede resumir en una frase que, desafortunadamente, no está a tono con el ánimo que supone la celebración de un cuadragésimo aniversario. Es la siguiente: algo no anda bien con la integración centroamericana; lejos de aprovechar el proceso para mejorar nuestra inserción en la economía global, esta última se suma a otros factores que tienden a debilitar la integración. Trátase de otra manera de sostener que estamos subaprovechando flagrantemente el potencial que ofrece la integración. Aunque no tengo propuestas acabadas para revertir esa tendencia, sí se me ocurren algunas pistas y orientaciones, y son ésas las que quisiera abordar con ustedes el día de hoy.

Empiezo con algo anecdótico. Tuve la oportunidad de asistir al Grupo Consultivo, celebrado en Madrid en marzo pasado. Esa reunión me provocó los mismos sentimientos de ambigüedad que la integración centroamericana me viene produciendo desde hace varios años. En sus aspectos formales, fue un encuentro que se desenvolvió con toda normalidad, sin sobresaltos ni inconvenientes. Centroamérica se presentó unida, y con un discurso más o menos coherente. La comunidad de donantes expresó - unos más que otrossu indeclinable apoyo a los países centroamericanos y al proceso de integración. Escuchamos discursos para levantar el ánimo, e incluso se identificaron temas de la mayor relevancia para el futuro desarrollo de la región. Al mismo tiempo, sin embargo, me quedé con la sensación que se había cumplido un ritual, pero que faltaba una fuerte dosis de convicción de ambos lados de la

2 En este contexto el concepto "regional” hace referencia a una agrupación de varios países del continente (Nota del editor). 
mesa (o sea, del lado de los centroamericanos, y también de las fuentes de financiamiento, sobre todo las bilaterales).

\section{La brecha entre el discurso y la acción}

Cuando uno vuelca la vista hacia la región, descubre la misma ambivalencia. Por un lado, el grado de interdependencia que se ha forjado a lo largo de los años sigue siendo elevado. Esa interdependencia tiene varias expresiones:

- El comercio recíproco (según la SIECA (Secretaría Permanente del Tratado General de la Integración Económica Centroamericana), 2,500 millones de dólares en el año 2000; o sea, la quinta parte de las exportaciones totales);

- Las masivas migraciones que se han dado entre algunos países fronterizos (por ejemplo, más de 400,000 nicaragüenses viviendo en Costa Rica);

- El surgimiento de empresas genuinamente transcentroamericanas;

- La creación de instituciones regionales; y,

- Una urdimbre de vasos comunicantes entre gremios privados y distintos segmentos de las sociedades civiles.

Pero, por otro lado, esa interdependencia se ve comprometida por las dificultades que revelan los países en actuar conjuntamente en sus negociaciones comerciales frente a terceros países (los casos de Chile y México), las violaciones unilaterales que periódicamente perforan el arancel común centroamericano, la mora en las contribuciones al sostenimiento de las instituciones regionales, y la actitud de "sálvese quien pueda", antes de la de cerrar filas ante la adversidad.

Asimismo, el grado de dependencia del comercio intracentroamericano varía mucho de un país a otro: desde más de la mitad de las exportaciones de bienes, en el caso de El Salvador, o hasta menos del $12 \%$ en el caso de Costa Rica (ambos para el año 2000). Por añadidura, los fenómenos descritos se ven condimentados con el resurgimiento de controversias fronterizas entre algunos países; controversias que parecían hasta hace poco cosas del pasado.

Todo lo anterior refleja un síndrome del cual padecemos desde hace mucho tiempo, y que se refleja en una creciente brecha entre el discurso y 
la acción; 0, si se quiere, entre la retórica y la realidad. Ello no significa que todos los centroamericanos somos hipócritas o cínicos. Sin duda, cuando los Presidentes firman una declaración política, los anima la mejor de las intenciones. Más bien, pienso que hay varias circunstancias que explican esa brecha. Es indispensable identificarlas, como el primer paso que los centroamericanos habremos de dar para aprovechar el potencial que la integración innegablemente tiene para ayudarnos a abordar con mayor éxito los tremendos desafíos que entraña funcionar en una economía global.

\section{Cuatro razones de este desfase}

A mi juicio, hay cuatro fenómenos principales que explican la brecha aludida. Primero, hemos subestimado las dificultades de la transición desde gobiernos autoritarios hacia gobiernos civiles, democráticamente electos. Sequndo, también hemos subestimado las dificultades de la transición económica que significa adaptarse a la globalización. Ello incluye una subestimación del grado de preparación necesario para insertarnos dinámicamente en la mundialización de la economía. Tercero, y quizás como reflejo de los dos fenómenos anteriores, se advierte un apoyo político insuficiente a las instituciones de la integración centroamericana, lo cual las ha mantenido en una situación de relativa debilidad. Y, por último, se destaca el hecho que los estímulos o impulsos que nos llegan del exterior hoy tienden a tener mayores efectos de dispersión que de agregación; o sea, tienden a dividirnos más que a unirnos. Comentaré brevemente cada uno de esos fenómenos a continuación.

En cuanto al primer aspecto (la difícil y compleja transición política), no cabe duda que uno de los logros más espectaculares de los últimos quince años fue el final de los conflictos armados y la transición desde gobiernos autoritarios en cuatro países hacia gobiernos civiles, democráticamente electos en todos ellos. En ese sentido, era razonable esperar un mayor grado de afinidad entre los cinco gobiernos de la región, y una elevada comunidad de intereses en todos los ordenes. Sin embargo, el tiempo ha demostrado que la consolidación de sistemas políticos democráticos ha avanzado a ritmos muy distintos entre un país y otro, y que, en rigor, sembrar una cultura democrática en sociedades donde antes apenas existía ha resultado más complejo y difícil de lo esperado. El tiempo y el esfuerzo dedicados a ese fin ha copado la atención de las máximas autoridades de varios gobiernos, muchas veces a costa de otras materias, incluyendo la agenda de la integra- 
ción centroamericana. Allí aparece una de las muchas expresiones de la brecha entre el discurso y la acción: los J efes de Estado asumen compromisos en sus reuniones regionales, inspirados por la euforia del momento y el respiro que éste les ofrece de sus labores cotidianas, pero al volver a sus respectivos países se enfrentan a la dura realidad política, que muchas veces desvía su atención hacia la coyuntura.

No estoy sugiriendo que existen oposiciones entre democracia política y la integración. Más bien, quisiera pensar que lo contrario es cierto. En la medida que el proceso de integración coadyuve en acelerar el crecimiento económico, también se constituye en un instrumento potencial para acelerar el desarrollo y la consolidación de sistemas políticos plurales, tolerantes y participativos. Pero, al parecer, ese vínculo no se ha establecido en la mente de la mayoría de los actores en los escenarios nacionales. Si ni siquiera se percibe con claridad cómo la integración contribuye a la expansión de las economías, el vínculo entre integración y democracia se presenta como algo aún más abstracto, a pesar de los objetivos enunciados en el Protocolo de Tegucigalpa, suscrito en diciembre de 1991 (donde se establece que el Sistema de la Integración centroamericana tiene por objetivo fundamental la realización de la integración de Centroamérica, para constituirla como Región de Paz, Libertad, Democracia y Desarrollo).

En relación al segundo aspecto (la gradual adaptación a la economía global), en las últimas dos décadas Centroamérica ha experimentado las mismas mutaciones en la política económica advertidas en el resto de América Latina para adaptarse al cambiante panorama internacional. En Centroamérica, como en el resto de la región, se aplicó una liberalización comercial unilateral -aunque parcialmente concertada en el marco del arancel común centroamericano -, un proceso de desregulación, la privatización de empresas públicas (con algunas excepciones), una política de "puertas abiertas" a la inversión extranjera directa, un continuo proceso de reforma fiscal, y cambios en la legislación laboral. Era de esperar, entonces, que el contexto de políticas macroeconómicas sería "amigable" a la integración, o al menos evitaría grandes diferencias que establecerían barreras artificiales en la asignación de recursos entre un país y otro, o que se constituirían, en los hechos, en obstáculos a la armonización de políticas.

Pero el ritmo, la secuencia, el alcance y la profundidad con queseaplicaron los cambios en la política económica variaron de un país a otro, al grado que, en algunos ámbitos, el grado de diferenciación en políticas es mayor en 2001 
de lo que lo era en 1990. Como ejemplos se pueden citar la política cambiaría, ahora que El Salvador optó por la dolarización y el resto de los países mantienen tasas de cambio flexibles, y el hecho que el coeficiente de tributación en Guatemala no llega al 10\%, frente a coeficientes que varían de $12 \%$ a $16 \%$ en el resto de los países. Por otra parte -y esto es el punto centralcon la posible excepción de Costa Rica, los avances en materia de diversificación y ampliación del sector exportador no fueron proporcionales a los esfuerzos emprendidos en materia de políticas. En efecto, se había subestimado lo difícil que resultaría acceder a mercados internacionales intensamente competitivos, y lo largo que resultaría la curva de aprendizaje.

De otra parte, se sigue subestimando aquella dificultad en uno de los dominios más importantes de la política pública: el fortalecimiento de las instituciones y de las organizaciones, públicas y privadas. Un ejemplo se encuentra en la debilidad que revelan los países centroamericanos para abordar las negociaciones comerciales que supone crear zonas de libre comercio con otros países, sean estos de alcance hemisférico (el ALCA) o con otros socios potenciales. Existe un contraste impresionante, por ejemplo, entre los modestos avances en construir nuestra capacidad negociadora ( $y$ cabe reconocer que algún avance se ha producido, aunque más en algunos países que en otros) y la manera que los países del CARICOM (Comunidad y Mercado Común del Caribe) se organizaron, a través del llamado Caribean Regional Negotiating Machinery (CRNM). Dicho de otra manera, no estamos ni remotamente preparados desde el punto de vista de la capacidad institucional para enfrentar los desafíos de la globalización.

Esa debilidad en el ámbito institucional me lleva al tercer aspecto: la falta de un apoyo político más decidido a las instituciones de la integración centroamericana. En vez de desarrollar instituciones comunes de excelencia que mitiguen las debilidades advertidas a nivel nacional, esa debilidad también se hace patente en nuestras instituciones regionales. Acaso es falta de tacto mencionarlo en el cuadragésimo aniversario de una de esas instituciones líderes, pero también sería una seria omisión no hacerlo. En general, las instituciones de la integración centroamericana no reciben suficiente financiamiento ni apoyo político para cumplir su cometido. La reforma institucional que resultó de la aplicación del Protocolo de Tegucigalpa, con la creación del Sistema de la Integración Centroamericana, no terminó con los traslapes $y$, a veces, las duplicaciones en el desarrollo de las actividades de la SIECA y del SICA (Sistema de Integración Centroamericana); así como de los Ministerios de Economía y de los Ministerios de Relaciones Exteriores. 
En lo puramente formal, el ordenamiento institucional se mueve en la dirección de una comunidad económica, pero, en la práctica, Centroamérica dista mucho de esa figura. Tanto el Parlamento Centroamericano como la Corte Centroamericana de Justicia son entidades que cumplen funciones formales -casi rituales- y que aún no reúnen en su seno a todos los países. También en general, y con algunas excepciones, las instituciones regionales carecen del liderazgo, capacidad de iniciativa y nivel de excelencia técnica que serían deseables. Cabría pensar que una presencia de instituciones regionales más proactivas podría contribuir poderosamente a cerrar la brecha entre la retórica y la realidad.

En cuarto y último lugar, y quizás como el elemento de mayor significación, pareciera que los estímulos o impulsos que nos llegan del exterior hoy tienden a tener mayores efectos de dispersión que de agregación. Para plantearlo crudamente, los países centroamericanos son socios en el comercio intrarregional, pero son esencialmente competidores para acceder a mercados externos. No por fuerza tendría que ser así, ya que hay mérito en el viejo dicho que "la unidad hace la fuerza": no es difícil imaginarse áreas donde la cooperación intrarregional facilitaría la inserción de todos y cada uno de los países en la economía mundial, empezando con el imperativo de negociar conjuntamente frente a terceros en vez de hacerlo de manera individual.

Pero el hecho es que algunos países están mucho mejor dotados para responder a los desafíos de la globalización que otros. Por ejemplo, los niveles educativos, la capacidad de la fuerza laboral y la fortaleza de sus instituciones democráticas, le otorgan a Costa Rica importantes ventajas en contraste a sus países vecinos. Es comprensible la tentación de capitalizar sobre esas ventajas comparativas de manera unilateral, frente al riesgo de diluirlas como parte de un promedio abstracto a nivel Centroamericano.

El mismo dilema del interés nacional frente a la solidaridad regional a veces se presenta en materia de acceso a recursos. El ejemplo más reciente, y no muy edificante, fue el marcado enfoque nacional que algunos países centroamericanos adoptaron en búsqueda de cooperación externa para atender los daños ocasionados por el huracán "Mitch" en 1998. Dicho de otra manera, la respuesta en materia de política económica a fenómenos de origen externo frecuentemente lleva a los gobiernos a buscar respuestas unilaterales, 0 a nivel nacional, en vez de pensar en respuestas multilaterales, a nivel regional. 
En resumen, desde el punto de vista intelectual los centroamericanos reconocemos que los desafíos de la globalización son, en verdad, muy distintos a los desafíos que la región enfrentaba hace cuarenta, o incluso hace diez años. No obstante, frecuentemente abordamos esos desafíos con la estructura mental de antaño, y no con la actitud que exige el mundo del Siglo XXI. Tendemos a subestimar la dificultad de transitar de la inercia del pasado a las exigencias del futuro. Afirmamos, como que si fuera cosa de simple voluntad, que accederemos a la economía global, o a una zona de libre comercio de alcance hemisférico, pero apenas disponemos de los medios para hacerlo, y demostramos cierta renuencia para prepararnos adecuadamente. Ni los gobiernos tienen la capacidad negociadora, ni el sector privado la capacidad para adaptarse rápidamente a las exigencias de un mercado mucho más competitivo.

Pero, gústenos o no, el proceso de globalización es irreversible. De manera que la prioridad número uno para la región es reducir la brecha entre la retórica y la realidad, preparándose, en serio, para funcionar en el mundo del Siglo XXI. No cabe duda que la integración centroamericana puede ser un factor de signo altamente positivo en recorrer el difícil camino que separa la actitud mental de antaño y la del futuro.

\section{Algunas líneas de avance para Centroamérica}

¿Pero, como capitalizar lo más posible sobre ese potencial? Ya hay un conjunto de propuestas sobre la mesa, y cada una apunta en la dirección correcta. Empieza con el planteamiento elaborado por la CEPAL en 1993 denominado "Centroamérica: el camino de los noventa", que pretende ofrecer un marco de referencia para salirle al paso a la globalización, y concluye con la recién elaborada propuesta del SICA denominada "Marco Estratégico para la transformación y modernización de Centroamérica en el siglo XXI", pasando por el documento del INCAE (Instituto Centroamericano de Administración de Empresas) denominado "Centroamérica en el Siglo XXI: Una agenda para la competitividad y el desarrollo sostenible". Al mismo tiempo, han surgido iniciativas más puntuales, como aquellas que emanan del Centro Latinoamericano para la Competitividad y el Desarrollo Sostenible, patrocinado por el INCAE y el BCIE, así como el Ilamado Plan PueblaPanamá, centrado fundamentalmente en el desarrollo de la infraestructura, y que se presenta como un complemento a la propuesta del SICA. Sin embargo, al parecer ninguna de estas propuestas ha sido asimilada lo 
suficiente en las políticas adoptadas a nivel de los países. Ello tan solo es otro reflejo de la brecha entre el discurso y la realidad.

A mi juicio, hay seis ámbitos en que cabría insistir en promover "amarres" entre un enfoque regional y las políticas -explícitas o implícitas- adoptadas a nivel de cada país.

El primero de esos ámbitos consiste en profundizar las democracias emergentes de la mayoría de los países centroamericanos (y consolidar la bien asentada cultura democrática en Costa Rica). Ello no sólo tiene un valor intrínseco, sino que contribuye a mejorar el contexto en que la región pretende mejorar su competitividad internacional. La estabilidad política, la cohesión social, el fortalecimiento de las instituciones, la confiabilidad en un régimen de derecho y la seguridad ciudadana son, todos, elementos indispensables que determinarán si la región constituye un espacio geográfico capaz de alentar la inversión nacional y atraer inversión internacional en nuevas actividades productivas. Si bien se ha avanzado mucho en esta materia, no es menos cierto que aún queda un largo trecho por recorrer medido desde la óptica de las exigencias de la globalización. Parece estar superada la idea secular que la evolución política de cada país es una cuestión puramente soberana e interna. Hoy por hoy la consolidación de las democracias en todos y cada uno de los países debe ser una preocupación legítima de interés mancomunado.

El segundo ámbito consiste en la necesidad de fortalecer las instituciones y organizaciones de cada país, y particularmente a las instituciones públicas. En los últimos quince a veinte años, y no obstante serios esfuerzos de modernización de las instituciones del Estado (incluyendo la privatización de empresas públicas) en todos los países de la región, se advierten insuficientes avances, e incluso en algunos países el panorama se agravó. De ahí que será indispensable convertir a los gobiernos centroamericanos en agentes a los que debe exigirse los mismos niveles de eficiencia y eficacia que a los agentes privados, precisamenteen aquellas áreas del quehacer nacional que corresponden a la actividad pública en una economía moderna. Hay experiencias relativamente exitosas en esta materia en otros países dentro y fuera de América Latina que podrían constituir una buena base de cooperación horizontal.

El tercer ámbito se encuentra en el imperativo de acortar el rezago tecnológico de las empresas centroamericanas y de generar empleo productivo. Relativamente pocas empresas se han colocado en la frontera de la 
productividad o de las "mejores prácticas" a nivel internacional, según se desprende del "Indice de Competitividad" que el INCAE prepara anualmente desde 1995 para los países de la región, con base en la metodo logía diseñada por el Foro Económico Mundial. Afortunadamente, sin embargo, en cada país hay un número de empresas que podrían llamarse "pro-activas" frente a los desafíos de la globalización. Estas empresas han asimilado técnicas de organización modernas, han aplicado tecnologías de punta al proceso productivo, y se han sujetado a normas de producción y de comercialización internacional. Han demostrado que, aun para productos básicos que tradicionalmente han respondido a las ventajas comparativas de la región -por ejemplo, el azúcar- es posible elevar la productividad de manera significativa. También han demostrado que existe una muy incipiente capacidad de innovación. En consecuencia, el acceso a mercados con productos no tradicionales ha crecido. Las empresas pro-activas no se limitan, como sería de suponer, a la categoría de grandes compañías. En Guatemala, por ejemplo, hay experiencias interesantes de pequeños empresarios, e incluso empresas cooperativas, que han tenido éxito en producir y exportar hortalizas y frutas. En definitiva, hay suficiente experiencia de signo positivo como para demostrar: primero, que es posible adquirir competitividad aceptable a nivel de empresa; $y$, segundo, que esas experiencias pueden servir como fuente de inspiración para que se produzca un efecto de emulación entre el resto del universo de empresas.

Pero desafortunadamente la vasta mayoría de las empresas, y sobre todo las microempresas que forman parte de ese universo, están muy lejos de adquirir niveles de productividad que les permitan sustituir importaciones de manera eficiente o competir en mercados internacionales. Algunas, las menos, adquieren una actitud defensiva frente a la competencia internacional, y se adaptan parcialmente a la necesidad de sobrevivir. Otras, las más, están en una actitud más bien pasiva, con serio riesgo de sucumbir ante la presión directa o indirecta de una economía internacional mucho más competitiva que antaño. Por añadidura, éstas últimas actúan de distintos mecanismos de protección frente a la competencia externa, lo cual a veces contrarresta los esfuerzos de acercarse a mayores grados de competitividad internacional.

De otra parte, las actividades "modernas" no generan suficientes puestos de trabajo para absorber la población económicamente activa emergente, la cual encuentra refugio en actividades de baja productividad y reducida retribución en el sector informal urbano y, a veces, en la agricultura de 
subsistencia. Allí radica la principal explicación de la elevada incidencia de la pobreza que continúa registrándose en toda la región.

De ahí que, aunque suene a algo consabido, quizás el mayor desafío que la globalización le plantea a las economías centroamericanas es a nivel microeconómico: obligar a las empresas, existentes y futuras, a aplicar tecnologías "duras" y "suaves" (capital y formas de gestión) a sus procesos productivos para elevar su productividad y estar en condiciones de competir, tanto en su mercado nacional, el mercado regional y el mercado internacional. Trátase, obviamente, de otra tarea donde la cooperación intracentroamericana puede jugar un papel fundamental.

El cuarto ámbito de preocupaciones se encuentra en cómo reducir las desigualdades sociales. Como se sabe, las sociedades centroamericanas, con la notable excepción de Costa Rica, se caracterizan por su notoria desigualdad. En la actualidad, y según la CEPAL, más de 20 millones de centroamericanos viven en situación de pobreza, de los cuales 14 millones viven en condición de indigencia. Hay grupos especialmente vulnerables, incluyendo mujeres, niños, y comunidades indígenas. Ello plantea dilemas éticos y morales a la consolidación de los sistemas políticos democráticos, así como dilemas de política económica sobre cómo conciliar objetivos de crecimiento con objetivos de mayor equidad. Con todo, y como elemento de signo positivo, muchas de las políticas que habrán de instrumentarse para responder a los desafíos de la globalización, como por ejemplo inversiones en la calidad de los recursos humanos de la región (educación, salud) serán funcionales tanto a los objetivos de crecimiento como de equidad, y deben constituirse en materias de primera prioridad.

El quinto ámbito de preocupaciones se refiere a la gestión macroeconómica para lograr estabilidad financiera, una expansión económica dinámica, y mayores niveles de ahorro y de inversión. Otra manera de plantearse el tema, en el marco de la globalización, es cómo evitar los seculares desequilibrios, tanto en la cuenta corriente del balance de pagos y, en especial, en las finanzas públicas. De por sí, la mayoría de los países siguen revelando serias fragilidades en ese flanco, con sistemas impositivos débiles (el caso más dramático es Guatemala, con un coeficiente de tributación de menos del 10\%) o déficit fiscales de cierta consideración. En efecto, la estabilidad del escenario macroeconómico es condición necesaria para responder al resto de los desafíos antes enumerados. Además de baja inflación y equilibrio fiscal, cabe mantener un déficit sostenible en cuenta corriente, un nivel de ahorro 
interno acorde con el proceso de inversión, preservación de un adecuado tipo de cambio real y cercanía de la demanda agregada a la plena utilización de la capacidad productiva existente. De nuevo, podemos hacer funcionar la integración para apoyar estos objetivos, a través de la aplicación de las "mejores prácticas" de cualquier país en la región en los demás (claro está, con las adaptaciones que exigen las diferentes realidades nacionales).

Por último, ya hemos avanzado en incorporar a la agenda regional la defensa del medio ambiente y los recursos naturales de Centroamérica, los cuales han sido agredidos por actores en ambos extremos de la estructura de ingresos. Los pobres, sobre todo en el área rural, tienden a ocupar las tierras de mala calidad, muchas veces en laderas, contribuyendo a la deforestación y a elevados grados de erosión y pérdida de suelos. También cubren buena parte de sus recursos energéticos mediante el uso de la leña; otro factor que contribuye a la deforestación. Las empresas agrícolas modernas incurren en una sobreexplotación de recursos naturales, frecuentemente con tecnología poco racionales desde el punto ambiental, incluyendo el uso incontrolado de agroquímicos.

En general, la región sufre de altas tasas de deforestación, degradación de la tierra, deterioro de las cuencas, pérdida de biodiversidad, contaminación de los ríos, lagos y zonas costeras. En las áreas urbanas se presenta una creciente contaminación del aire debido a actividades industriales, el tráfico vehicular, la generación de electricidad y las industrias de servicios. También se presentan pérdidas de suelo debido a asentamientos humanos no planificados, se genera un enorme volumen de basura, que incluye residuos peligrosos, con una notable falta de capacidad de recolección.

El grado de deterioro ha llegado a tal punto que, en los últimos años, se empieza a perfilar cierta conciencia ambiental, y la necesidad de abordar el desarrollo de una manera ambientalmente sustentable. Se refleja en los compromisos adoptados por los Gobiernos de Centroamérica, Panamá y Belice a través de la llamada "Alianza Centroamericana para el Desarrollo Sostenible". Si bien se trata de un concepto integral de desarrollo, que abarca aspectos económicos, sociales, políticos y culturales, los compromisos contienen cierto énfasis en el manejo sostenible de los recursos naturales y mejora de la calidad ambiental.

Pero, no obstante la creación de instancias regionales, como la Comisión Centroamericana de Ambiente y Desarrollo y el Consejo Centroamericano de Bosques y Áreas Protegidas (esteúltimo maneja proyectos como el Corredor 
Biológico Mesoamericano), muchos de los compromisos adquiridos hasta ahora van poco más allá de declaraciones de buenas intenciones. La falta de recursos, relativamente poco apoyo de la sociedad civil, legislación deficiente 0 carente de regulaciones precisas y poca capacidad institucional son algunos de los obstáculos a que el desarrollo en Centroamérica sea más ambientalmente racional. En consecuencia, es indispensable revertir esa tendencia.

Para terminar, cabe insistir que debemos aprovechar la integración para mejorar nuestra participación en la economía mundial. Ello requiere definir la agenda de la integración en términos de identificar aquellos aspectos susceptibles de derivar ventajas de trabajar conjuntamente, frente a la alternativa dehacerlo cada país en forma individual. Parte del trabajo técnico que demuestra esas ventajas ya existe, aunque seguramente hay asignaturas pendientes. También hace falta un mayor nivel de concientización a nivel de cada país sobre el potencial del trabajo conjunto. Precisamente, por eso, tenemos necesidad de instituciones regionales capaces y dispuestas a jugar un papel proactivo a favor del desarrollo y de la integración. Y, entre esas instituciones, destaca el Banco Centroamericano de Integración Económica que reúne en su seno la capacidad de proponer, la capacidad de promover, y la capacidad de cooperar, al ofrecer un punto de encuentro entre la comunidad de donantes y los países miembros del SICA en su propio seno. 